\title{
Training in Trauma Care
}

\author{
Arun Prasad
}

Received: 16 May 2012 / Accepted: 22 June 2012 /Published online: 4 July 2012

(C) Association of Surgeons of India 2012

\section{Dear Editor,}

I read the recent article on Training in Trauma Care [1] with great interest.

Trauma management of road traffic accidents has to be dealt with at various steps-starting from prevention of accidents, safety devices to reduce severity of trauma, training of first responders, transport of trauma victims, management at trauma center, and rehabilitation.

Medical colleges in India do not have a curriculum that teaches how to deal with a polytrauma patient [2]. There is no single teaching session where faculty from all specialties and superspecialties come together and train students on trauma care.

This is being done at various centers now as trauma courses such as PTC (primary trauma care course) and ATLS (advanced trauma and life support course).

We have been doing the primary trauma care training in association with Primary Trauma Care Foundation, the UK [3]. Over 1,000 medical and paramedical personnel have been trained over the past 7 years. We would like to share the following experience:

1. A first responder course is required to train people for dealing with a trauma victim on site. These responders can be security guards, policemen, ambulance and fire engine personnel.

\footnotetext{
A. Prasad $(\bowtie)$

Apollo Hospital,

Delhi, India

e-mail: laparoscopy@hotmail.com
}

2. Ambulance service is essential part of trauma care and training of ambulance staff is important.

3. Then comes the role of the casualty medical officer who receives the patient hopefully in the golden hour.

4. Hardware in terms of mannequins, airway equipment, cervical collar, splints, scoops, etc., is important to give hands-on training.

5. Simulated accident scenarios to be used for practical training.

6. More emphasis to practical training than lectures.

7. Getting the trainees to become trainers for future courses in order to enhance the impact of training.

8. Refresher courses are designed for faculty and delegates.

A comprehensive program has to be developed that covers all aspects of trauma care. Medical profession and public need to come together for the success of such a program.

\section{References}

1. Gore M (2012) Training in trauma care. Indian J Surg 74(2):128130

2. Das AK, Gupta SB, Joshi SR, Aggarwal P (2008) White paper on academic emergency medicine in India. J Assoc Physicians India 56:789-798

3. Wilkinson D, McDougall R (2007) Primary trauma care. Anaesthesia 62:61-64 